Texas A\&M University-San Antonio

Digital Commons @ Texas A\&M University-San Antonio

Special Education Faculty Publications College of Education and Human Development

5-20-2019

Practical Strategies for Improving Postsecondary Outcomes for Students with EBD

\author{
Mariya T. Davis \\ Texas A\&M University-San Antonio, Mariya.Davis@tamusa.edu \\ Ingrid K. Cumming \\ Orange County Public Schools
}

Follow this and additional works at: https://digitalcommons.tamusa.edu/sped_faculty

Part of the Special Education and Teaching Commons

\title{
Publisher Citation
}

Mariya T. Davis \& Ingrid K. Cumming (2019) Practical strategies for improving postsecondary outcomes for students with EBD, Preventing School Failure: Alternative Education for Children and Youth, DOI:

$10.1080 / 1045988 X .2019 .1608898$

This Article is brought to you for free and open access by the College of Education and Human Development at Digital Commons @ Texas A\&M University- San Antonio. It has been accepted for inclusion in Special Education Faculty Publications by an authorized administrator of Digital Commons @ Texas A\&M University- San Antonio. For more information, please contact deirdre.mcdonald@tamusa.edu. 
PRACTICAL STRATEGIES

Practical Strategies for Improving Postsecondary Outcomes for Students with EBD

\author{
Mariya T. Davis \\ Texas A\&M University, San Antonio \\ Ingrid K. Cumming \\ Orange County Public Schools
}

Address correspondence to Mariya T. Davis, One University Way, San Antonio, TX 78224, USA;

Mariya.Davis@tamusa.edu

Authors Notes:

Mariya Davis, Ph.D., is an Assistant Professor of Special Education at Texas A\&M University - San Antonio. Her research interests include transition to adulthood, student empowerment, family engagement, assessment in special education, inclusive practices for students with disabilities, and professional development. 
PRACTICAL STRATEGIES

\begin{abstract}
Transition from high school to adulthood is a difficult period of life for all youth, especially those with disabilities. Research indicates students with emotional and behavioral disorders (EBD) experience difficulties in transitioning to post-school environment. Their postschool outcomes in the areas of education, employment, and community participation continue to concern researchers, practitioners, and families and, therefore, demand improvement. Identification and implementation of transition-related evidence-based practices (EBPs) is essential for teachers who work with students with EBD to increase the likelihood of positive adult outcomes for these students. Discussed in this article are transition-related recommendations and practical strategies that may be used by teachers and other education professionals preparing students with EBD for life after school.
\end{abstract}

Keywords: emotional and behavioral disorders, EBD, transition, evidence-based practices 
PRACTICAL STRATEGIES

Practical Strategies for Improving Postsecondary Outcomes for Students with EBD

Transition from high school to adulthood is a difficult period of life for all adolescents, especially those with disabilities. The Individuals with Disabilities Education Act (IDEA) requires schools to provide students with disabilities transition services to ensure adequate preparation for life after school (IDEA, 2004). The federal law defines transition services as a coordinated set of activities focused on improving academic and functional achievement to facilitate movement from school to post-school education, employment, and independent living (20 U.S.C. $§ 1401 \mathrm{sec} .602$ [34]). The overall goal of transition planning is to prepare students with disabilities, including those with emotional and behavioral disorders (EBD), for adulthood and equip them with necessary skills for desirable outcomes.

Despite such federal regulations, postsecondary outcomes for students with EBD are among the poorest of any group of students with or without disabilities and continue to pose concerns for families, educators, and researchers (Wagner, 2014). Research indicates students with EBD are less likely to earn a diploma within eight years of high-school graduation (Newman, Wagner, Cameto, \& Knokey, 2009). Further, their participation in postsecondary education is lower than their peers without disabilities or peers with other disabilities (Wagner, 2014). Young adults with EBD have significantly lower employment rates: only $42 \%$ of young adults with EBD who had been out of high school up to four years reported to work full time (Wagner, 2014). In addition, young adults with EBD are less likely to live on their own after graduation: only $22 \%$ of young adults with EBD reported living independently four years after high school (Newman et al., 2009). Moreover, involvement with the criminal justice system is higher for young adults with EBD than those in other disability categories, which creates disruption to their educational programs, employment, and family life. 
PRACTICAL STRATEGIES

Educators must understand the contributing factors of dismal outcomes for students with EBD and make data-based decisions that will lead to their improved post-school experiences. To improve student outcomes, IDEA (2004) and Every Student Succeeds Act (ESSA, 2015) require the use of evidence-based practices (EBPs), treatments or approaches that have been found effective through replicated research (Boutot, Raulston, \& Dukes, 2017). The proper identification and implementation of effective transition strategies and resources is not only necessary but essential when it comes to the development and implementation of Individualized Education Programs (IEPs) and transition programs for students with EBD. The purpose of this article is to provide transition related recommendations, review practical strategies and EBPs, and supply resources that may be used by teachers and other education professionals preparing students with EBD for life after school.

\section{Recommendations for Practice}

Evaluation of post-school outcomes of young adults with EBD suggests their secondary education and systems of support are not sufficient in preparing them for adulthood and demand improvement. Several studies have examined factors predicting postsecondary outcomes for adolescents with EBD. For example, Test and colleagues (2009) described 16 evidence-based predictors of post-school employment, education, and independent living success for students with disabilities. In the current article, these predictors and corresponding recommendations for practice are organized around multiple environments, or ecological systems into four main categories: (a) individual skills; (b) family factors; (c) school factors; and (d) community factors (see Table 1). Table 1 illustrates EBPs that facilitates implementation of in-school predictors of post-school success, recommended practices, and links to additional web based resources that can assist in the transition planning process. 
PRACTICAL STRATEGIES

<INSERT TABLE 1 HERE>

\section{Individual Skills}

Research suggests adolescents with EBD demonstrate low self-determination and selfadvocacy skills and may be reluctant to disclose their disabilities at school and work (Cameto, Levine, \& Wagner, 2004); as a result, development of self-awareness, self-determination, and self-advocacy skills become increasingly important for these students. Self-determination and self-advocacy, "the ability to make choices, solve problems, set goals, evaluate options, take initiative to reach one's goals, and accept consequences of one's actions" (Rowe et al., 2015, p. 121), correlate with positive postsecondary education and employment outcomes (Test et al., 2009).

Self-determination instruction can be effective in helping students with EBD understand their disabilities and self-advocate for needed supports and services in school and beyond. One example of an effective practice for building and maintaining self-determination skills that teachers can implement with students with EBD is the Self-Directed IEP. The Self-Directed IEP is an EBP designed to encourage student self-determination that focuses on multiple sequential IEP meeting participation skills (e.g., introduction, performance review, setting goals, asking questions; Zarrow Center, n.d.). Research maintains the use of the Self-Directed IEP to teach students with EBD the skills needed to lead their own IEP meeting (Snyder, 2002). Adolescents who completed the Self-Directed IEP take ownership of their IEP meetings, attend more of their IEP meetings, discuss their career interests, share their goals and dreams about life after school, feel more confident in reaching those goals, and overall feel empowered (Sweeney, 1997). Thus, teachers need to facilitate active student involvement in their IEPs and provide opportunities for practicing self-determination skills. One tool that can be effectively used in this process is a 
PRACTICAL STRATEGIES

student-led IEP checklist (see Figure 1). By learning to lead and actively participate in their own IEP meetings, students have the opportunity to practice public speaking, self-advocacy, goal setting, and self-evaluation.

\section{<INSERT FIGURE 1 HERE>}

Self-management and self-regulation training can address deficits often exhibited by students with EBD (Denune et al., 2015). Utilizing self-monitoring procedures, students learn to assess their behavior and record the results. First, the teacher and the student select and define the behavior to be changed, and determine the criteria for mastery. They discuss what appropriate and inappropriate behaviors look like. Next, the teacher introduces the selfmanagement system (e.g., a self-monitoring form), and provides guided practice in both the desired behavior and how to complete the self-monitoring form. During the initial training phase, both the teacher and the student complete self-monitoring forms. Then, they compare the forms, with the teacher praising the student for exhibiting positive behaviors. Over time, the student learns to manage his behavior independently by using self-monitoring. As a result, selfmonitoring helps the student maintain and increase appropriate behaviors, which may lead to improved performance in his academic, behavioral, and social domains in school and beyond. Early interventions to develop organizational and social skills play a critical role in preparing students with EBD for transition to post-school environments. Social skills influence one's ability to advocate for personal needs through adolescence and adulthood and are increasingly important not only to higher academic achievement, but to attainment and retention of employment. Research suggests social skills interventions have been effective for students with EBD (Gresham, 2015). Social skills training (SST) is an example of an EBP designed to teach specific social skills that improve social development and reduce behavioral problems in 
PRACTICAL STRATEGIES

students with EBD. Most SST programs focus on skill acquisition and performance, reduction and elimination of problem behaviors, and generalization and maintenance of social skills (Cook et al., 2008). For example, the teacher can implement SST to support students with reduction and elimination of their behavioral outbursts with role-playing scenarios and identification of alternative solutions to outbursts.

The review of rate and quality of community engagement among adolescents with EBD suggests they benefit from opportunities to develop independent living skills. A high school student with EBD currently living in his family home, may be interested in eventually living in his own apartment and having his own car. With the help of his teacher, the student works on his independent living skills (e.g., using transportation, acquiring a stable living situation, and managing basic finances), which could affect his employment and participation in postsecondary education and community. To build student autonomy and decision making, it is important that teachers provide students with information about postsecondary education and employment options, skills needed to get and keep a job, reasonable accommodations, options for transportation, types of housing, and developing financial literacy skills (Rowe, McNaught, Yoho, Davis, \& Mazzotti, 2018). Career awareness is an understanding of the numerous possibilities for employment and the knowledge of skills needed to begin working in an identified career field. Developing career awareness involves learning about opportunities, education, and the skills needed in a variety of occupational pathways to choose a career that matches with one's strengths and interests (Rowe et al, 2018).

The existing plethora of web-based resources available to adolescents with disabilities help them explore postsecondary education, employment, and independent living options; however, some of the information may be unreliable or misleading. When evaluating web-based 
PRACTICAL STRATEGIES

transition resources, students need to be taught to search for "key information that increases their confidence about the relevance, usefulness, and accuracy of the content being presented" (Rowe et al., 2018, p. 253). For more strategies on how to implement the transition from school to postschool life and help adolescents build autonomy, make informed decisions, and gain information via web-based resources see Rowe et al. (2018).

As such, teaching self-determination, self-management, social skills, independent living skills, and career awareness are some of the most essential teacher-facilitated elements of transition planning. Students with EBD need to be provided with numerous opportunities to learn and cultivate these skills. Additional recommendation and resources for building individual skills are provided in Table 1.

\section{Family Factors}

Successful transition to adulthood often requires collaboration between families and school (Ruffolo, Kuhn, \& Evans, 2006). Parental involvement, defined as "parents, families, guardians are active and knowledgeable participants in all aspects of transition planning (e.g., decision-making, maintaining interest, attending meetings, and advocating for their child)" (Rowe et al., 2015, p. 122), is a strong predictor of successful transition to adult life for all students, including those with EBD (Test et al., 2009). Given the role families play in transition planning and the multifaceted process of transition, it is important to consider available family partnership models for transition planning and services. According to one family partnership model, it befits teachers and other education professionals to use the following 10 strategies influencing collaborative partnerships with families: (a) student- and family-centered approach; (b) shared vision; (c) cultural responsiveness; (d) proactive communication; (e) commitment and care; (f) creative problem solving; (g) providing choices; (h) making connections; (i) taking 
PRACTICAL STRATEGIES

actions; and (j) reflecting and celebrating (CEC, 2009). Teachers can use these strategies to increase parental involvement that promises to produce positive post-school outcomes for students with EBD.

Furthermore, in preparation for the IEP meeting, teachers can ask parents to complete a parent input form that helps in evaluation of student employability skills and instructional planning (see Figure 2 for details).

\section{<INSERT FIGURE 2 HERE>}

Teachers may provide parents with suggested questions before and after the IEP meeting to assist them in preparation for establishing transition and post-school goals. In addition to encouraging family involvement in the transition process and increasing family awareness of post-school experiences of adolescents with EBD, teachers may facilitate family access to various community resources, information, and training. Assistance with locating community support systems (e.g., behavioral health services, vocational rehabilitation, housing) can improve both transition services for students with EBD and collaboration between teachers and families. Additional recommendations and resources on how to promote parental involvement are provided in Table 1.

\section{School Factors}

Improving post-school outcomes for adolescents with EBD requires improving the services they receive in high school. These services include establishing effective procedures for transition, providing follow up on former students, and enhanced training for teachers in mainstream schools (Hornby \& Witte, 2008). Considering that positive teacher-student relationships equate to improved student outcomes and appear to have the greatest influence on the transition experiences of students with EBD (O'Riordan, 2011), cultivation of these 
PRACTICAL STRATEGIES

relationships becomes increasingly important in today's schools. One EBP teachers may consider is Check \& Connect, a structured intervention model designed to assist schools in identifying students who are at risk for dropping out of school, then pairing those students with mentors who address each student's individual needs to help them progress toward school completion (Christenson et al., 2008). Check \& Connect consists of four components:

1. A mentor who keeps education salient for students.

2. Systematic monitoring.

3. Timely and individualized intervention.

4. Enhancing home-school communication and a home environment for learning.

When implementing the core elements of Check \& Connect, teachers need to focus on relationship building, problem-solving skills, and student perseverance for academic motivation. Another strategy is to teach students goal-setting and goal-attainment skills. Specifically, students should be taught to set SMART goals (i.e., specific, measurable, achievable, relevant, and timely), monitor their progress toward mastering those goals, evaluating the results, and communicating this information to their parents and other IEP team members. See Figure 4 for an example of a SMART transition goal for a student desiring to attain a part-time job in the field of cosmetology.

\section{<INSERT FIGURE 3 HERE>}

To provide comprehensive individualized assistance to adolescents with EBD, schools can employ a team-based problem solving approach that involves not only teachers, but also professionals from other disciplines. The development of effective, intensive, collaborative school-based mental health programs has the potential to meet the emotional and academic needs of these adolescents and improve their post-school outcomes (Kutash, Duchnowski, \& Green, 
PRACTICAL STRATEGIES

2011). For example, school professionals may incorporate mental health and counseling services in student IEPs if deemed beneficial. As the student transitions to a post-school environment, collaborative efforts between the school and a community-based mental health agency will ensure a continuation of services for managing his or her emotional health and overall wellbeing.

Adolescents with EBD experience significant difficulties transitioning from school to work (Nochasjski \& Schweitzer, 2014). The School to Work Transition Program (STWTP) provides relevant activities and additional opportunities for students with EBD which promote successful transition to the role of a worker. The objectives of STWTP include developing, implementing and, refining a model that: (a) identifies and explores a student's vocational interests, aptitudes, and abilities, (b) identifies and addresses each student's obstacles or barriers to successful employment, (c) teaches students skills and behaviors needed to participate successfully in a chosen work field, (d) provide students with opportunities to practice learned skills and behaviors in a realistic work environment, (e) identifies long term vocational goals for students, and (f) acquaints students and their families with adult service agencies in the community that focused on work opportunities and supports (Nochasjski \& Schweitzer, 2014).

In phase one of the STWTP (i.e., school-based learning), the teacher may explore student vocational interests, identify barriers to successful employment, and teach the student skills needed to successfully participate in a chosen work setting. In phase two (i.e., community involvement), the teacher facilitates student volunteering at a community business related to his or her area of interest. The concluding steps are to prepare the student for the final phase of STWTP (i.e., work-based learning and independent employment in the local community) that provide opportunity to practice learned skills in a work environment with the help of job coaches 
PRACTICAL STRATEGIES

and peer role models (phase three) and competitive employment (phase four). The STWTP is guided by best practices that are correlated with post-school employment outcomes for youth with disabilities. Students participating in a STWTP increase their recognition and value of work that leads toward an occupation (Nochasjski \& Schweitzer, 2014). Additional recommendations and resources for building transition related individual skills are provided in Table 1.

\section{Community Factors}

In order to increase positive post-school outcomes, schools and communities must increase their collaborative efforts and provide meaningful community-based experiences for student with EBD. Community experiences are defined as "activities occurring outside the school setting, complemented with in-class instruction, where students apply academic, social, and/or general work behaviors and skills" (Rowe et al., 2015, p. 120) and can be used to teach and monitor the attainment of desired student behaviors and skills.

To improve outcomes for adolescents with EBD and provide for them within the context of their families and communities, research suggest the use of Wraparound, a team-based service planning and coordination process (Chitiyo, 2014). Wraparound consists of four phases including: (a) engagement and team preparation; (b) initial plan development; (c) plan implementation and refinement; and (d) transition. This culturally relevant and uniquely designed plan builds constructive relationships and support networks around the adolescents and his or her family while increasing effective school completion, employment, and postsecondary education participation. Wraparound can be implemented as an intensive level of intervention in school-wide positive behavioral interventions. Focus on engaging the student, family, and teacher equally in a proactive team process is a critical feature of the Wraparound process. Other 
PRACTICAL STRATEGIES

important aspects of Wraparound include improvements in quality of life, regular progress monitoring, and frequent meetings to design unique strategies.

Wraparound goes beyond the IEP to include resources and services for home and community settings. By utilizing the Wraparound approach, teachers are able to construct one integrated plan that addresses student's unique needs in more than one life domain. The unique design and cultural relevance of Wraparound allow building constructive relationships and networks around the student and his family while increasing effective school completion, employment, and postsecondary education participation.

Within social networks students establish similar ties and interests within their interpersonal relationships. Social networks are important, yet can be daunting to students as they traverse their school community. Social networks can be established from shared personal interests, sports, and academic achievements. Students may cluster in cliques or communities based on their individual skills or personal connections (Tompson, Kahn, Falk, Vettel, \& Bassett, 2019). Students with disabilities, including those with EBD, benefit from social networks and interactions when they are planned and sustained. The connections to others with similar interests reflect a social network which is critical for student success while in school and beyond.

In order to identify available community support systems that match student specific needs, teachers may consider conducting a community mapping survey (see Figure 4). By visiting locations within the community and interviewing personnel, teachers are able to collect comprehensive information that help to align the community resources with the student's transition-related areas of need. Additional strategies and internet sources related to community factors can be found in Table 1. These internet resources include instructions for implementation 
PRACTICAL STRATEGIES

of EBPs, lesson plans, guidelines and checklists, training modules, and additional references pertinent to effective transition.

\section{<INSERT FIGURE 4 HERE >}

\section{Limitations}

The results of the current study examining practical strategies for improving postsecondary outcomes for students with EBD are limited by several factors. First, this study was not intended to be a comprehensive review of all literature related to effective postsecondary transition for students with EBD. While the recommendations provided in this study do not represent an exhaustive list, they can be a starting place for school professionals to support students with EBD in preparation for demanding post-school environments.

Second, a related limiting factor involves limited literature on transitioning students with EBD into post-school environments. Specifically, research on transition EBPs for students with EBD is scarce. Therefore, the authors used available relevant research in order to identify effective transition-related strategies and practices that could be used to increase the likelihood of enhanced postsecondary outcomes for students with EBD.

Third, listed transition strategies and practices were not addressed in great details. The authors provided examples and practical tools (e.g., transition goal, IEP checklist, input form) school professionals can use in transition planning and supplied addition web-based resources for further exploration. Finally, the identified transition strategies and practices might be similar or overlap with those recommended for students with other disabilities.

\section{Implications}

Despite such limitations, this study has several implications for research and practice. First, this study adds to previous research on effective transition for students with EBD. Drawing on 
PRACTICAL STRATEGIES

support from current literature related to evidence-based predictors of post-school outcomes, as well as specific literature targeting students with EBD, authors proposed a conceptual framework of transition practices organized around multiple environments, or ecological systems, into four main categories (i.e., individual skills, and family, school, and community factors) and provided corresponding recommendations for practice. In addition, the results of this study might provide support for researchers focusing on bridging secondary and postsecondary services for students with EBD.

Next, the authors emphasized on identifying strategies and resources that are efficacious and useful for teachers and other school professionals preparing students with EBD for life after school. Teachers and other school professionals working with students with EBD may find helpful the practical tools depicted in this study, EBPs that facilitates implementation of inschool predictors of post-school success, and links to additional web-based resources that can assist in the transition planning process. The authors anticipate that school practitioners will explore reported practices and resources to meet the needs of students with EBD and utilize them for creating individualized transition programs for these students. In addition, the described transition practices may benefit not only students with EBD, but also other students with and without disabilities.

Finally, the results of this study may have implications for school and district administrators. School administrators may want to explore new ways to support teachers and other school professionals who prepare students with EBD for adulthood. For example, relevant professional development (e.g., using transition-related assessment in making data-driven programming decisions, effective methods for implementing transition-related practices in school settings and ensuring high fidelity in the process) may enhance transition-related 
PRACTICAL STRATEGIES

knowledge and skills of school professionals and facilitate successful transition into adulthood for students with EBD.

\section{Future Directions}

Given the paucity of studies focusing on the needs of students with EBD during transition to adulthood and dismal outcomes they experience in post-school environments, the need for additional research focused on effective transition practices for meeting the needs of students with EBD remains highly important. First, additional research is needed to more deeply address each of the reported EBPs and practices and describe effective methods for their implementation. For example, a detailed explanation of the Wraparound plan and step-by-step description how to implement it with students with EBD may be helpful for teachers and other school professionals. Since self-determination, self-advocacy, and other individual skills positively correlate with positive outcomes for students with disabilities (Test et al., 2009), more research is needed to determine how to integrate relevant strategies into secondary school curriculum to promote student competence and foster successful transition to post-school environments.

One important responsibility for future researchers is not only to conduct studies that meet high quality standards, but also to translate research to practice and provide school professionals with practical tools for implementation in the school setting. Researchers should provide explanation how to implement transition-related practices in school settings with high fidelity. Future research should also consider exploring the use of assessment in the transition planning process for students with EBD and providing a detailed description of one or two assessment tools supported with fill-in blank forms, examples, and vignettes or case studies. Because students with EBD comprise a heterogeneous group of individuals with different need and ability levels, teachers and other school professionals may also benefit from research-to-practice studies 
PRACTICAL STRATEGIES

exploring practical strategies of meeting transition needs of students with EBD through the multilevel systems of support.

Future research should also explore the impact of early transition in promoting post-school success of students with EBD. One example would be to address transition services in middle school so that the students can make adequate progress toward their postsecondary goals. Some services, aimed at improvement of individual skills that require years to nurture and develop, should begin in elementary school. Further studies should be conducted to find consistency between high school and post-school settings to ensure students with EBD experience smoother transition between the two settings.

Finally, future research should employ methods that provide insight on training for teachers and other school professionals on evidence-based transition practices for students with EBD. Future research should also focus on the perceptions of secondary teachers on the barriers to effective transition to post-school environments. Teachers may not be aware how to facilitate transition practices in their classrooms (Webb, Patterson, Syverud, \& Seabrooks-Blackmore, 2008; Morningstar \& Benitez, 2013); therefore, further research is necessary to address the area of training for teachers and other professionals working with students with EBD.

\section{Conclusion}

Postsecondary experiences of adolescents with EBD in the areas of employment, postsecondary education, and community involvement pose concerns for families, educators, and researchers. Effective programs must be designed for students with EBD to ensure their positive adult outcomes. The proper identification and implementation of effective transition strategies and resources is not only necessary but essential when it comes to the development and implementation of individualized transition programs for students with EBD. Presented in this 
PRACTICAL STRATEGIES

article are recommendations and resources that can be used by educators as a springboard in

furthering their transition knowledge and skills. Using strategies and transition-related

recommendations discussed in this article, teachers and other education professionals can

strengthen the transition planning process for students with EBD, which translates into improved post-school outcomes and enhanced quality of life. 
PRACTICAL STRATEGIES

\section{References}

Boutot, E. A., Raulston, T. J., \& Dukes, C. (2017). Evidence-based practices for educating students with Autism Spectrum Disorders. In E. A. Boutot (Eds.), Autism spectrum disorders: Foundations, characteristics, and effective strategies (pp. 21-39). Upper Saddle River, N.J.: Pearson/Prentice Hall

Cameto, R., Levine, P., \& Wagner, M. (2004). Transition planning for students with disabilities. Retrieved from http://files.eric.ed.gov/fulltext/ED496547.pdf

Chitiyo, J. (2014). The wraparound process for adolescents with severe emotional behavioral disorders. Journal of Research in Special Educational Needs, 14(2), 105-109. doi: $10.1111 / 1471-3802.12008$

Christenson, S. L., Thurlow, M. L., Sinclair, M. F., Lehr, C. A., Kaibel, C. M., Reschly, A. L., Mavis, A., \& Pohl, A. (2008). Check \& Connect: A comprehensive student engagement intervention manual. Retrieved from http://www.checkandconnect.org/publications/default.html\#manual.

Cook, C. R., Gresham, F. M., Kern, L., Barreras, R. B., Thornton, S., \& Crews, S. D. (2008). Social Skills Training for secondary students with emotional and/or behavioral disorders: A review and analysis of the meta-analytic literature. Journal of Emotional and Behavioral Disorders, 16(3), 131-144. doi: 10.1177/1063426608314541

Council for Exceptional Children (2009). Building family partnerships. Retrieved from https://tooloftheweek.org/building-family-partnerships/

Denune, H., Hawkins, R., Donovan, L., Mccoy, D., Hall, L., \& Moeder, A. (2015). Combining self-monitoring and an interdependent group contingency to improve the behavior of sixth graders with EBD. Psychology in the Schools, 52(6), 562-577. doi:10.1002/pits.21846 
PRACTICAL STRATEGIES

Gresham, F. (2015). Evidence-based social skills interventions for students at risk for EBD. Remedial and Special Education, 36(2), 100-104. doi: 10.1177/0741932514556183

Hornby, G., \& Witte, C. (2008). Follow-up study of ex-students of a residential school for children with emotional and behavioural difficulties in New Zealand. Emotional \& Behavioural Difficulties, 13(2), 79-93. doi: 10.1080/13632750802027598

Individuals with Disabilities Education Improvement Act of 2004. 108-446, 118 Stat. 2647 (2004). Retrieved from http://www.copyright.gov/legislation/pl108-446.pdf

Kutash, K., Duchnowski, A. J., \& Green, A. L. (2011). School-based mental health programs for students who have emotional disturbances: Academic and social-emotional outcomes. School Mental Health, 3(4), 191-208. doi:10.1007/s12310-011-9062-9

Morningstar, M. E., \& Benitez, D. T. (2013). Teacher training matters: The results of a multistate survey of secondary special educators regarding transition from school to adulthood. Teacher Education and Special Education, 36(1), 51-64.

Newman, L., Wagner, M., Cameto, R., \& Knokey, A-M. (2009). The post-high school outcomes of adolescents with disabilities up to 4 years after high school. Retrieved from http://ies.ed.gov/ncser/pdf/20093017.pdf

Nochajski, S. M., \& Schweitzer, J. A. (2014). Promoting school to work transition for students with emotional/behavioral disorders. Work, 48(3), 413-422. doi:10.3233/WOR-131790

O'Riordan, Z. (2011). Living in the 'real world': the experiences and support of school-leavers with social, emotional and behavioural difficulties. Emotional \& Behavioural Difficulties, 16(3), 303-316. doi:10.1080/13632752.2011.595097

Rowe, D., Alverson, C., Unruh, D., Fowler, C., Kellems, R., \& Test, D. (2015). A Delphi study to operationalize evidence-based predictors in secondary transition. Career Development 
PRACTICAL STRATEGIES

and Transition for Exceptional Individuals, 38(2), 113-126. doi:

$10.1080 / 13632750802027598$

Rowe, D., McNaught, J., Yoho, L., Davis, M., \& Mazzotti, V. (2018). Helping students make informed decisions about transition via web-based resources. Career Development and Transition for Exceptional Individuals, 41(4), 252-259. doi: 10.1177/2165143417736266

Ruffolo, M., Kuhn, M., \& Evans, M. (2006). Developing a parent-professional team leadership model in group work: work with families with children experiencing behavioral and emotional problems. Social Work, 51(1), 39-47 9p. doi: sw/51.1.39

Snyder, E. P. (2002). Teaching students with combined behavioral disorders and mental retardation to lead their own IEP meetings. Behavioral Disorders, 27(4), 340-357.

Sweeney, M. A. (1997). The effects of self-determination training on student involvement in the IEP process. Florida State University, Tallahassee.

Test, D. W., Mazzotti, V. L., Mustian, A. L., Fowler, C. H., Kortering, L., \& Kohler, P. (2009). Evidence-based secondary transition predictors for improving post-school outcomes for students with disabilities. Career Development for Exceptional Individuals, 32(3), 160181. doi: $10.1177 / 0885728809346960$

Tompson, S. H., Kahn, A. E., Falk, E. B., Vettel, J. M., \& Bassett, D. S. (2019). Individual differences in learning social and nonsocial network structures. Journal of Experimental Psychology: Learning, Memory, and Cognition, 45(2), 253-271. https://doiorg.ezproxy.net.ucf.edu/10.1037/xlm0000580

Wagner, M. (2014). Longitudinal outcomes and post-high school status of students with Emotional d Behavioral Disorders. In H. M. Walker, \& F. M. Gresham (Eds.), Handbook 
PRACTICAL STRATEGIES

of evidence-based practices for Emotional and Behavioral Disorders: Applications in schools. (p. 86-103). New York: Guildford.

Webb, K. W., Patterson, K. B., Syverud, S., \& Seabrooks-Blackmore, J. (2008). Evidenced practices that promote transition to postsecondary education: Listening to a decade of expert voices. Exceptionality, 16(4), 192-206. doi:10.1080/09362830802412182

Zarrow Center (n.d.). Self-directed IEP. Retrieved from http://www.ou.edu/education/centersand-partnerships/zarrow/choicemaker-curriculum/self-directed-iep 
PRACTICAL STRATEGIES

Table 1.

Predictors, Recommended Practices, and Resources

\begin{tabular}{|c|c|c|}
\hline Predictors & Recommendations for practice & EBPs and additional resources \\
\hline $\begin{array}{l}\text { Family-related } \\
\text { predictors: } \\
\text { parent expectations } \\
\text { parental involvement }\end{array}$ & $\begin{array}{l}\text { - Assess families' needs and preferences } \\
\text { - Help families build personal, professional, and } \\
\text { community networks } \\
\text { - Engage families throughout the IEP process }\end{array}$ & $\begin{array}{l}\text { - Transition Planning Folder } \\
\text { http://www.nsttac.org/content/transition-planning-folder- } \\
\text { mapping-out-your-childs-transition } \\
\text { - Resources from the Technical Assistance on Transition }\end{array}$ \\
\hline
\end{tabular}




\begin{tabular}{|c|c|c|}
\hline & $\begin{array}{l}\text { and mentorship programs } \\
\text { - Evaluate parent involvement activities and } \\
\text { strategies. } \\
\text { - Become familiar with resources on developing } \\
\text { family-professional partnerships. } \\
\text { - Develop materials and identify training to } \\
\text { promote parental participation in the IEP and } \\
\text { transition planning process. } \\
\text { - Encourage parents to attend workshops on } \\
\text { transition planning. } \\
\text { - Contact parents in the early stages of the IEP } \\
\text { and incorporate parental input for the IEP. } \\
\text { - Help families understand the importance of } \\
\text { having high expectations for their child and } \\
\text { make a fully informed decision. } \\
\text { - Remember that the most involved family } \\
\text { members may be parents, extended family } \\
\text { members, friends, or others that regard } \\
\text { themselves as family. }\end{array}$ & $\begin{array}{l}\text { and the Rehabilitation Act: http://www.pacer.org/tatra/ } \\
\text { - Information regarding community resource mapping } \\
\text { www.transcen.org } \\
\text { - Information from the Regional Educational Laboratory } \\
\text { Northwest: http://educationnorthwest.org/ } \\
\text { - Resources from U.S. Department's Office of Special } \\
\text { Education Programs and parent training centers } \\
\text { http://www.parentcenternetwork.org/ } \\
\text {-Resources from the Beach Center } \\
\text { http://www.beachcenter.org/families/partnerships/family } \\
\text { professional partnerships.aspx } \\
\text {-Resources from the National Secondary Transition } \\
\text { Technical Assistance Center (NSTTAC) } \\
\text { http://www.nsttac.org/content/parent-and-family- } \\
\underline{\text { involvement-annotatedbibliography-prepared-nsttac- }} \\
\text { dawn-rowe, } \\
\underline{\text { http://www.nsttac.org/content/evidence-based-practices- }} \\
\underline{\text { secondary-transition }}\end{array}$ \\
\hline $\begin{array}{l}\text { Structural school- } \\
\text { based predictors: } \\
\text { inclusion in general } \\
\text { education classes } \\
\text { exit exam } \\
\text { requirements/high } \\
\text { school diploma status } \\
\text { occupational courses }\end{array}$ & $\begin{array}{l}\text { - Ensure access and necessary support in } \\
\text { general education curriculum } \\
\text { - Provide student access to rigorous academic } \\
\text { instruction } \\
\text { - Facilitate school-engagement and build } \\
\text { support network (e.g., Check \& Connect) } \\
\text { - Provide instruction in soft skills (e.g., problem } \\
\text { solving) and specific vocational skills (e.g., } \\
\text { machine operation) } \\
\text { - Provide opportunity for school-to-work } \\
\text { including career development through job } \\
\text { shadowing, work- } \\
\text { study, internships, or volunteering. }\end{array}$ & $\begin{array}{l}\text { - Check and Connect } \\
\text { - Self-Determined Learning Model of Instruction } \\
\text { (SDLMI) } \\
\text { - Mnemonic Strategies, Peer-Assisted Instruction, Self- } \\
\text { Management, Visual Displays, and Technology-Based } \\
\text { Interventions (academic skills) } \\
\text { - Resources on school completion and dropout prevention } \\
\text { www.ndpc-sd.org, } \\
\text { www.dropoutprevention.org } \\
\text { - Resources for SDLMI: } \\
\underline{\text { http://www.beachcenter.org/wisdom_based_action/the_se }} \\
\text { determined_learning_model_of_instruction/default.aspx }\end{array}$ \\
\hline
\end{tabular}




\begin{tabular}{|c|c|c|}
\hline & $\begin{array}{l}\text { - Support students through school-based mental } \\
\text { health programs } \\
\text { - Provide professional development for staff }\end{array}$ & $\begin{array}{l}\text { - Resources on college and career preparation } \\
\text { www.ccrscenter.org, } \\
\underline{\text { http://www.betterhighschools.org/CCR/documents/NHS }} \\
\underline{\text { C_CCROrganizerIntroBrief_2012.pdf }}\end{array}$ \\
\hline $\begin{array}{l}\text { Community-based } \\
\text { predictors: } \\
\text { interagency } \\
\text { collaboration } \\
\text { paid employment/work } \\
\text { experience } \\
\text { student support }\end{array}$ & $\begin{array}{l}\text { - Assess to determine required job-related skills } \\
\text { - Ensure opportunity for paid employment/work } \\
\text { study } \\
\text { and community work-based program } \\
\text { - Build supportive student network } \\
\text { - Provide opportunities for meaningful } \\
\text { community engagement in the community (e.g., } \\
\text { sports, clubs) } \\
\text { - Use appropriate community services and } \\
\text { supports to meet individual needs }\end{array}$ & 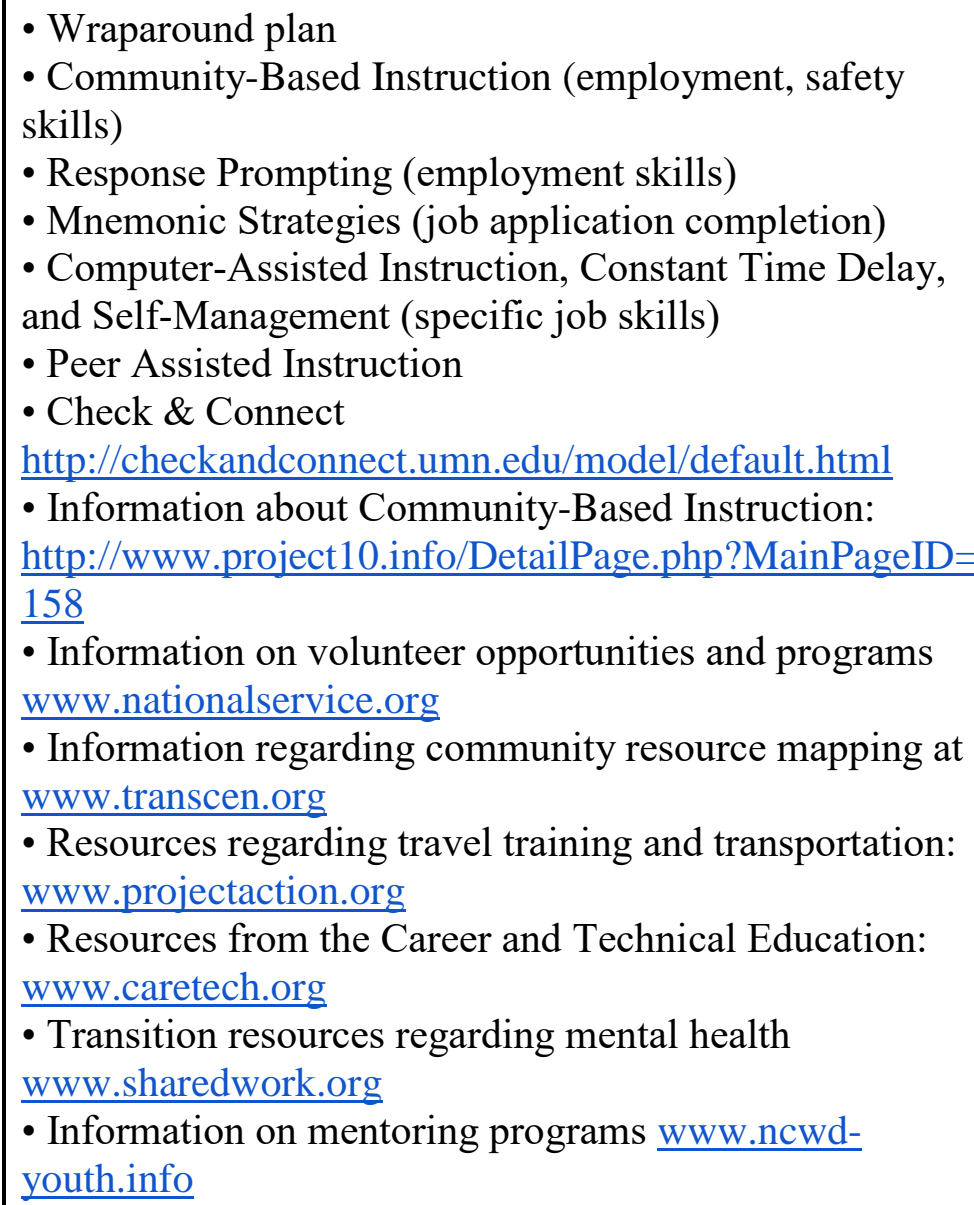 \\
\hline
\end{tabular}

Note: NSTTAC website resources were used in the development of this table. 